\title{
Difficult mask ventilation in general surgical population: \\ observation of risk factors and predictors [version 1; peer
}

\section{review: 2 approved]}

\author{
Davide Cattano (D1, Peter V. Killoran1, Chunyan Cai², Anastasia D. Katsiampoura1, \\ Ruggero M. Corso ${ }^{3}$, Carin A. Hagberg ${ }^{1}$ \\ ${ }^{1}$ Department of Anesthesiology, University of Texas Medical School at Houston, Houston, TX, 77030, USA \\ ${ }^{2}$ Division of Clinical and Translational Sciences, , Department of Internal Medicine, University of Texas Medical School at Houston, \\ Houston, TX, 77030, USA \\ ${ }^{3}$ Emergency Department, Anesthesia and Intensive Care Section, "GB Morgagni - L Pierantoni” Hospital, Forli, 47121, Italy
}

V1 First published: 27 Aug 2014, 3:204

https://doi.org/10.12688/f1000research.5131.1

Latest published: 27 Aug 2014, 3:204

https://doi.org/10.12688/f1000research.5131.1

\section{Abstract}

Background: There are few predictors of difficult mask ventilation and a simple, objective, predictive system to identify patients at risk of difficult mask ventilation does not currently exist. We present a retrospective - subgroup analysis aimed at identifying predictive factors for difficult mask ventilation (DMV) in patients undergoing preoperative airway assessment before elective surgery at a major teaching hospital.

Methods: Data for this retrospective analysis were derived from a database of airway assessments, management plans, and outcomes that were collected prospectively from August 2008 to May 2010 at a Level 1 academic trauma center. Patients were stratified into two groups based on the difficulty of mask ventilation and the cohorts were analyzed using univariate analysis and stepwise selection method.

Results: A total of 1399 pre-operative assessments were completed with documentation stating that mask ventilation was attempted. Of those 1399,124 (8.9\%) patients were found to be difficult to mask ventilate. A comparison of patients with and without difficult mask ventilation identified seven risk factors for DMV: age, body mass index (BMI), neck circumference, history of difficult intubation, presence of facial hair, perceived short neck and obstructive sleep apnea.

Although seven risk factors were identified, no individual subject had more than four risk factors.

Conclusion: The results of this study confirm that in a real world clinical setting, the incidence of DMV is not negligible and suggest the use of a simple bedside predictive score to improve the accuracy of DMV prediction, thereby improving patient safety. Further prospective studies to validate this score would be useful.

\section{Open Peer Review \\ Approval Status \\ 1 \\ 2 \\ version 1 \\ 27 Aug 2014

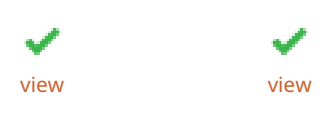 \\ 1. D John Doyle, Cleveland Clinic Main Campus, Cleveland, USA \\ 2. Adrian Matioc, William S. Middleton Memorial Veterans Medical Center, Madison, USA}

Any reports and responses or comments on the article can be found at the end of the article. 


\section{Keywords}

airway management, preoperative airway assessment, difficult mask ventilation

\section{Corresponding author: Davide Cattano (Davide.Cattano@uth.tmc.edu)}

Competing interests: No competing interests were disclosed.

Grant information: The present work was supported by internal funds of the Department of Anesthesiology, University of Texas Medical School at Houston and the Foundation for Anesthesia Research, and Education (FAER). Dr. Killoran was supported by a training fellowship from the Keck Center NLM Training Program in Biomedical Informatics of the Gulft Coast Consortia (NLM grant no.

T15LM007093). Dr. Cai's research was supported by the National Institutes of Health's Clinical and Translational Science Award grant (UL1 TR000371), awarded to the University of Texas Health Science Center at Houston in 2012 by the National Center for Clinical and Translational Sciences. Dr. Cattano receives grant support from Karl Storz Endoskope Inc. Dr. Hagberg was the recipient of the 2007 Foundation for Anesthesia Education and Research (FAER) Grant and currently receives grant support from AMBU, Covidien, and Karl Storz Endoskopy. She serves on the speaker bureau for Covidien, LMA North America, and Ambus A/S.

The funders had no role in study design, data collection and analysis, decision to publish, or preparation of the manuscript.

Copyright: ( 2014 Cattano D et al. This is an open access article distributed under the terms of the Creative Commons Attribution License, which permits unrestricted use, distribution, and reproduction in any medium, provided the original work is properly cited. Data associated with the article are available under the terms of the Creative Commons Zero "No rights reserved" data waiver (CC0 1.0 Public domain dedication).

How to cite this article: Cattano D, Killoran PV, Cai C et al. Difficult mask ventilation in general surgical population: observation of risk factors and predictors [version 1; peer review: 2 approved] F1000Research 2014, 3:204

https://doi.org/10.12688/f1000research.5131.1

First published: 27 Aug 2014, 3:204 https://doi.org/10.12688/f1000research.5131.1 


\section{Introduction}

One of the primary responsibilities of an anesthesiologist is to maintain adequate oxygenation and ventilation by maintaining a patent upper airway ${ }^{1}$. Being able to provide ventilation by bag-mask, in face of a difficult or failed tracheal intubation, can make the difference between serious complications and disability.

In the literature, the incidence of difficult mask ventilation (DMV) varies from $0.08 \%$ to $15 \%$ depending on the definition used ${ }^{1-4}$. Despite its importance, there are few predictors of $\mathrm{DMV}^{2-4}$ and a simple, objective, predictive score to identify patients at risk of DMV at the bedside does not currently exist.

We present a retrospective-subgroup analysis of patients undergoing preoperative airway assessment before elective surgery ${ }^{5}$ at a major teaching hospital, to identify predictive factors for DMV and evaluate a composite score value, based on a comprehensive airway assessment and recorded outcomes.

\section{Materials and methods}

Data for this retrospective analysis were derived from a database of airway assessments, management plans, and outcomes collected prospectively from August 2008 to May 2010 at a Level 1 academic trauma center (Memorial Hermann Hospital, Texas Medical Center, Houston, TX, USA). The study was sponsored by an educational grant from the Foundation for Anesthesia, Education and Research (FAER), and other educational funds from the Department of Anesthesiology at University of Texas Medical School at Houston. After obtaining IRB approval (HSC-MS-07-0144) all non-obstetric adult patients presenting for elective surgery requiring general anesthesia, were enrolled in this study ${ }^{5}$.

A total of 91 residents were involved in the data collection process. Residents were randomized into two groups — an experimental group of residents who used a comprehensive airway assessment form in addition to the existing anesthesia record, and a control group, who only used the existing anesthesia record. For the purpose of the present analysis, only the experiment group data were used for a total of 1339 recorded and attempted bag mask ventilations, graded and assigned to a pre-operative airway assessment ${ }^{5}$.

DMV was defined as difficulty in maintaining a mask seal and obtaining a satisfactory capnography (end-tidal $\mathrm{CO}_{2}$ and tidal volume) ${ }^{6}$. If mask ventilation was attempted, then its easiness was determined and graded based on a severity score: from easy $=0$, oral airway used $=1$; to difficult, two handed ventilation $=2$, or extraglottic device required $=3$. However, the use of neuromuscular blocking agent, type, dosage, time of administration, and rescue was not considered in the analysis.

Descriptive statistics mean \pm standard deviation for continuous variables and frequency (percentage) for categorical variables was summarized for all pre-operative patient characteristics. Univariate analysis of comparison between patients with or without DMV was performed using the two sample t-test for continuous variables and the Chi-square test or Fisher exact test for categorical variables. In addition, receiver operating characteristic (ROC) curves were used to assess the discrimination ability of predicting DMV using continuous variables and to determine their best thresholds which maximize the sum of sensitivity and specificity. All dichotomized variables with a p-value $<0.10$ in univariate analysis were entered into a multivariate logistic regression model. A stepwise selection method was used to identify independent predictors of difficult mask ventilation. The adjusted odds ratios and their 95\% confidence intervals $(\mathrm{CI})$ were reported for each independent predictor. The area under a ROC curve or c-statistic was calculated to evaluate the resulting model's predictive value.

A non-weighted risk score was created by assigning one point to each independent predictor. In addition, a weighted score introduced in Kheterparl et al. (2009) was derived based on the coefficients of independent predictors from the logistic regression model ${ }^{8}$. The comparison between non-weighted and weighted risk scores was evaluated through c-statistic. All statistical analyses were conducted using SAS 9.3 (SAS Institute, Cary, NC, USA). A p-value $<0.05$ was considered significant.

\section{Results}

A total of 1399 pre-operative assessments were completed with documentation that MV was attempted, an ultimate outcome was graded, and the record was linked to a pre-operative airway assessment. Of 1399 patients, $124(8.9 \%)$ were found to be difficult to mask ventilate ( 2 and 3 , Table 1 ). Once stratified into two groups based on the difficulty of mask ventilation the cohorts were analyzed.

Based on univariate analysis (Table 2), a total of eight factors were identified with a p-value <0.05: age, gender, BMI, neck circumference, history of difficult intubation, presence of facial hair, perceived short neck and obstructive sleep apnea (OSA, suspected or diagnosed). The thresholds that maximized the sum of sensitivity and specificity were 47 (year) for age, $35\left(\mathrm{~kg} / \mathrm{m}^{2}\right)$ for BMI, and $40(\mathrm{~cm})$ for Neck Circumference by analyzing the ROC curve of each continuous risk factor to predict DMV. In addition to these significant factors, an additional variable capturing the absence of dentition $(p=0.09)$ was included in the subsequent analysis. Entering all these nine factors into a multivariate logistic regression model, seven independent risks factors for DMV were identified using stepwise selection: age of 47 year or older, BMI of $35 \mathrm{~kg} / \mathrm{m}^{2}$ or greater, and neck circumference of $40 \mathrm{~cm}$ or higher, history of difficult intubation, presence of facial hair, perceived short neck,

Table 1. Summary statistics for MVEase.

\begin{tabular}{|l|c|}
\hline MVEase & $\begin{array}{c}\text { Frequency (percentage) } \\
\mathbf{N = 1 3 9 9}\end{array}$ \\
\hline $0=$ easy & $752(53.8)$ \\
\hline $1=$ Oral airway used & $523(37.4)$ \\
\hline $2=$ Two handed ventilation & $118(8.4)$ \\
\hline $\begin{array}{l}3=\text { Extraglottic device } \\
\text { required }\end{array}$ & $6(0.4)$ \\
\hline
\end{tabular}

* Mask ventilation was considered easy for MVEase classes 0 and 1 and difficult for MVEase classes 2 and 3. Local practice patterns often include placement of an oral airway for routine bag mask ventilation. 
Table 2. Preoperative patient characteristics by DMV status.

\begin{tabular}{|c|c|c|c|}
\hline \multirow[b]{2}{*}{ Variables } & \multicolumn{2}{|c|}{ DMV } & \multirow[b]{2}{*}{ p-value } \\
\hline & $\begin{array}{c}\text { False } \\
\text { (MVEase }=0,1) \\
\mathrm{N}=1275\end{array}$ & $\begin{array}{c}\text { True } \\
\text { (MVEase }=2,3 \text { ) } \\
\text { N=124 }\end{array}$ & \\
\hline $\begin{array}{l}\text { Age (year) } \\
\geq 47\end{array}$ & $\begin{array}{c}46 \pm 17 \\
614(48.2)\end{array}$ & $\begin{array}{c}49 \pm 13 \\
80(64.5)\end{array}$ & $\begin{array}{l}0.034 \\
0.001\end{array}$ \\
\hline Male & 628 (49.3) & 78 (62.9) & 0.004 \\
\hline $\begin{array}{l}\text { BMI }\left(\mathbf{k g} / \mathrm{m}^{2}\right) \\
\geq 35\end{array}$ & $\begin{array}{c}29.1 \pm 7.2 \\
234(18.4)\end{array}$ & $\begin{array}{l}33.2 \pm 8.0 \\
46(37.1)\end{array}$ & $\begin{array}{l}<0.0001 \\
<0.0001\end{array}$ \\
\hline $\begin{array}{l}\text { NeckCirc } \\
\geq 40\end{array}$ & $\begin{array}{l}39.2 \pm 4.8 \\
588(46.1)\end{array}$ & $\begin{array}{l}42.9 \pm 4.7 \\
96(77.4)\end{array}$ & $\begin{array}{l}<0.0001 \\
<0.0001\end{array}$ \\
\hline Interlncisors & $4.7 \pm 1.0$ & $4.8 \pm 0.9$ & 0.204 \\
\hline Thyromental & $7.9 \pm 1.7$ & $7.9 \pm 1.7$ & 0.769 \\
\hline Sternomental & $15.3 \pm 2.3$ & $15.3 \pm 2.1$ & 0.757 \\
\hline HxDiffIntub & $7(0.6)$ & $4(3.2)$ & 0.012 \\
\hline $\begin{array}{l}\text { NeckMobGrade } \\
1 \\
2,3\end{array}$ & $\begin{array}{c}1131(88.7) \\
144(11.3)\end{array}$ & $\begin{array}{c}106(85.5) \\
18(14.5)\end{array}$ & 0.284 \\
\hline $\begin{array}{l}\text { Mallampati } \\
\text { I, II } \\
\text { III, IV }\end{array}$ & $\begin{array}{c}1081(84.8) \\
194(15.2)\end{array}$ & $\begin{array}{l}100(80.7) \\
24(19.4)\end{array}$ & 0.225 \\
\hline CSpineAbn & $40(3.1)$ & $7(5.7)$ & 0.183 \\
\hline NoTeeth & $107(8.4)$ & $16(12.9)$ & 0.090 \\
\hline FacHair & $126(9.9)$ & $29(23.4)$ & $<0.0001$ \\
\hline FacTrauma & $18(1.4)$ & $0(0)$ & NR \\
\hline FullStomach & $6(0.5)$ & $1(0.8)$ & 0.479 \\
\hline NasalDef & $5(0.4)$ & $1(0.8)$ & 0.428 \\
\hline NeckTrauma & $17(1.3)$ & $3(2.4)$ & 0.413 \\
\hline ShortNeck & $69(5.4)$ & $22(17.7)$ & $<0.0001$ \\
\hline ObsSA & 198 (15.5) & $41(33.1)$ & $<0.0001$ \\
\hline $\begin{array}{l}\text { ResYear } \\
\text { CA-1, CA-1-2 } \\
\text { CA-2, CA-2-3, CA-3 }\end{array}$ & $\begin{array}{l}980(76.9) \\
295(23.1)\end{array}$ & $\begin{array}{l}92(74.2) \\
32(25.8)\end{array}$ & 0.503 \\
\hline
\end{tabular}

NR: not reported due to zero cells. Values are reported as mean $\pm \mathrm{SD}$ and frequency (percentage). and OSA; $\mathrm{p}<0.001$; (Table 3). The model's c-statistic is 0.75 (95\% CI: 0.71-0.79), demonstrating a good discriminating capacity. The adjusted odds ratios are also presented in Table 3.

The seven independent risk factors identified were then applied to all cases where DMV was encountered to evaluate a predictive model for DMV. Although seven risks factors were identified, no individual subject had more than four risk factors. As indicated, non-weighted and weighted risk score were created based on these seven risk factors. The model's c-statistic based on unweighted score is 0.70 (95\% CI: 0.66-0.74) (Figure 1). Weighted score did not improve the prediction performance, which model's c-statistic is 0.70 (95\% CI: 0.66-0.75). Therefore, we adopted the simple approach of unweighted risk score for the following analysis. The sensitivity, specificity, likelihood ratios, and predictive values were progressively calculated for patients with different number of risk factors (Table 4). The best cut-off for the number of risk factors was 2 , which maximizes Youden's index ${ }^{16}$ with sensitivity of 0.65 and specificity of 0.67 . Table 5 also shows the distribution frequencies

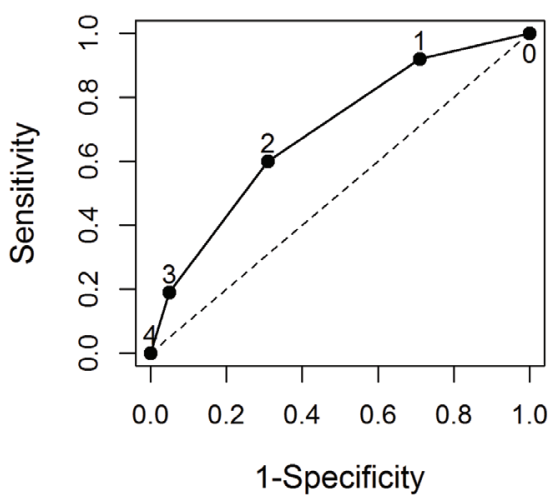

Figure 1. A receiver-operating-characteristic (ROC) curve evaluating the sensitivity and specificity of pre-operative independent risk factors for difficult mask ventilation (DMV). Seven independent predictors for difficult mask ventilation were identified using logistic regression: age of $47 \mathrm{yr}$ or older, BMI of $35 \mathrm{~kg} / \mathrm{m}^{2}$ or greater, NeckCirc of 40 or greater, HxDifflntub, FacHair, short neck and OSA. A risk score for DMV was calculated based on the number of these seven risk factors a patient possessed. The area under the curve was $0.70 \pm 0.02$.

Table 3. Seven independent predictors of difficult mask ventilation.

\begin{tabular}{|l|c|c|c|c|}
\hline Predictor & $\boldsymbol{\beta}$ Coefficient & $\begin{array}{c}\text { Standard } \\
\text { Error }\end{array}$ & $\boldsymbol{p}$-value & $\begin{array}{c}\text { Adjusted odds ratio } \\
\text { (95\% Confidence }\end{array}$ \\
\hline Interval)
\end{tabular}




\begin{abstract}
Table 4. Diagnostic value of the cut-off for number of risk factors in predicting a difficult
\end{abstract} mask ventilation.

\begin{tabular}{|c|c|c|c|c|c|c|}
\hline $\begin{array}{l}\text { Cut-off for } \\
\text { number of } \\
\text { risk factors }\end{array}$ & Sensitivity & Specificity & $\begin{array}{l}\text { Likelihood } \\
\text { ratio } \\
\text { positive }\end{array}$ & $\begin{array}{l}\text { Likelihood } \\
\text { ratio } \\
\text { negative }\end{array}$ & $\begin{array}{l}\text { Positive } \\
\text { predictive } \\
\text { value }\end{array}$ & $\begin{array}{l}\text { Negative } \\
\text { predictive } \\
\text { value }\end{array}$ \\
\hline 1 & 0.94 & 0.26 & 1.27 & 0.23 & 0.11 & 0.98 \\
\hline 2 & 0.65 & 0.67 & 1.97 & 0.52 & 0.16 & 0.95 \\
\hline 3 & 0.19 & 0.95 & 3.80 & 0.85 & 0.26 & 0.92 \\
\hline 4 & 0.00 & 1.00 & $\mathrm{~N} / \mathrm{A}$ & 1.0 & 0.00 & 0.91 \\
\hline
\end{tabular}

Likelihood ratio positive $=$ Sensitivity $/(1-$ Specificity $)$ Likelihood ratio negative $=(1$-Sensitivity $) /$ Specificity N/A: not applicable

Table 5. Odds ratio of patients with a given risk level (i.e., number of risk factors at $1,2,3$ ) to a patient with 0 risk factor.

\begin{tabular}{|l|l|l|l|}
$\begin{array}{l}\text { Number of } \\
\text { risk factors }\end{array}$ & $\begin{array}{l}\text { Total } \\
\text { patients }\end{array}$ & $\begin{array}{l}\text { Patients } \\
\text { with DMV } \\
\text { n (\%) }\end{array}$ & $\begin{array}{l}\text { Odds Ratio (95\% } \\
\text { Confidence Interval) }\end{array}$ \\
\hline 0 & 337 & $7(2.1)$ & Referrence \\
\hline 1 & 559 & $36(6.4)$ & $3.25(1.43,7.38)$ \\
\hline 2 & 410 & $57(13.9)$ & $7.61(3.42,16.93)$ \\
\hline 3 & 93 & $24(25.8)$ & $16.40(6.79,39.57)$ \\
\hline
\end{tabular}

of different number of risk factors and the odds ratio for patients with one, two, or three risk factors relative to a patient with zero risk factors. When compared with zero risk factors, patients with two or more risk factors have an odds ratio of 7.6 (95\% CI: 3.4-16.9).

\section{Discussion}

For more than three decades, poor airway management was recognized as a serious patient safety concern, emphasizing the need for a careful airway assessment and identifying the predictors for a difficult airway ${ }^{6}$. Moreover, the airway risk assessment tools in widespread use were mostly focused on one specific aspect of a difficult airway (i.e. difficult laryngoscopy, difficult intubation). In more recent years, this paradigm has shifted to a more functional approach with greater emphasis placed on the overall importance of the airway patency. Indeed, due to early data demonstrating the significant risk of respiratory depression associated with sedation, The Joint Commission and Centers for Medicare and Medicaid Services has implemented policies to ensure evaluation of the risk for a difficult airway prior to procedures. Moreover, the 2013 American Society of Anesthesiology (ASA) Practice Guidelines for Management of the Difficult Airway caution about the risks of a difficult bag-mask ventilation due to upper airway obstruction and recommend an airway risk assessment before every anesthesia procedure is performed ${ }^{7}$. In this study, we determine that: (1) the reported incidence of DMV was 9\%; (2) the reported incidence of DMV in patients with a history of OSA was 17\%; (3) seven independent risk factors were identified (age $\geq 47 \mathrm{yr}, \mathrm{BMI} \geq 35 \mathrm{~kg} / \mathrm{m}^{2}$, neck circumference $\geq 40 \mathrm{~cm}$, history of difficult intubation, presence of facial hair, perceived short neck, history of OSA); (4) the absence of three of these factors allows to reasonably exclude a DMV (likelihood ratio negative: 0.85 ).

Recent investigations have demonstrated that the incidence and risk factors for DMV are distinct from difficult laryngoscopy (DL) predictors (incidence i.e. ranges from $1.4 \%^{8}$ to $16 \%{ }^{9}$ ). There are many reasons that can explain these findings: (1) absence of a universally accepted definition of DMV (different definitions lead to different data); (2) obesity and OSA are undoubtedly predictors of DMV, therefore a study done on a population with a high prevalence of obesity will show a higher incidence of DMV from a population with a lower prevalence of obesity; (3) the design of face masks and the technique used are not usually reported, but recent studies highlight their importance for performance and accordingly the reported incidence of $\mathrm{DMV}^{10,11}$; (4) the influence of neuromuscular block on mask ventilation has been demonstrated, but often these data are missing ${ }^{12}$.

We confirmed many factors such as age, short neck, facial hair, BMI, but most importantly neck circumference, that have been associated with difficult airway in the obese ${ }^{13,14}$ as well as a history of OSA. Interestingly, neck circumference and BMI are also important determinants for OSA screening, which may results in some overlap between OSA and DMV. Our study confirmed that OSA patients are at risk for DMV, calling for a systematic screening for OSA with the aim to identify a category of patients at risk of not only difficult airway, but also of post-operative complications ${ }^{15}$.

We attempted, indeed, to define a bedside score to predict DMV: our score has the advantage of including objective variables, such as neck circumference, but has a high false positive rate, possibly limiting the usefulness for a large-scale clinical implementation of the score. However with a sensitivity of $92 \%$ (using one risk factor, while it drops at lower values for two or more combined risk factors), this score could actually be useful as screening tool, since avoiding the underestimation of unpredicted DMV is far more important than a false positive (particularly in airway management where there are not significant costs attributed to overestimation).

Our study also has other limitations: first, only DMV outcomes were analyzed without consideration for difficult laryngoscopy; second, a large number of records were selectively removed from 
our analysis because the outcomes were not known, reducing our statistical power and introducing the possibility of selection bias.

The results of this study confirm that in a real world clinical setting, the incidence of DMV is not negligible and suggest the use of a simple bedside predictive score to improve the accuracy of DMV prediction, thereby improving patient safety. Further prospective studies to validate this score would be useful.

\section{Data availability}

Data have been obtained from databases at the Memorial Hermann Hospital, Texas Medical Center, Houston, IRB approval HSCMS-07-0144. The author can support applications to the Institutional Board to make the data accessible upon individual request.

\section{Author contributions}

Cattano: design, study monitoring, data interpretation, manuscript writing.

Chunyan: data quality, statistical analysis, data interpretation, manuscript writing.

Corso: data interpretation, manuscript writing.

Killoran: data quality, data interpretation.

Katsiampoura: manuscript preparation.
Hagberg: design, manuscript preparation.

All authors read and approved the final content of the manuscript.

\section{Competing interests}

No competing interests were disclosed.

\section{Grant information}

The present work was supported by internal funds of the Department of Anesthesiology, University of Texas Medical School at Houston and the Foundation for Anesthesia Research, and Education (FAER). Dr. Killoran was supported by a training fellowship from the Keck Center NLM Training Program in Biomedical Informatics of the Gulft Coast Consortia (NLM grant no. T15LM007093). Dr. Cai's research was supported by the National Institutes of Health's Clinical and Translational Science Award grant (UL1 TR000371), awarded to the University of Texas Health Science Center at Houston in 2012 by the National Center for Clinical and Translational Sciences. Dr. Cattano receives grant support from Karl Storz Endoskope Inc. Dr. Hagberg was the recipient of the 2007 Foundation for Anesthesia Education and Research (FAER) Grant and currently receives grant support from AMBU, Covidien, and Karl Storz Endoskopy. She serves on the speaker bureau for Covidien, LMA North America, and Ambus A/S.

The funders had no role in study design, data collection and analysis, decision to publish, or preparation of the manuscript.
1. El-Orbany M, Woehlck HJ: Difficult mask ventilation. Anesth Analg. 2009; 109(6): 1870-80.

PubMed Abstract | Publisher Full Text

2. Langeron $\mathrm{O}$, Masso $\mathrm{E}$, Huraux $\mathrm{C}$, et al.: Prediction of difficult mask ventilation. Anesthesiology. 2000; 92(5): 1229-36. PubMed Abstract | Publisher Full Tex

3. Kheterpal S, Han R, Tremper K, et al: Incidence and predictors of difficult and impossible mask ventilation. Anesthesiology. 2006; 105(5): 885-91. PubMed Abstract | Publisher Full Text

4. Kheterpal S, Healy D, Aziz MF, et al:: Multicenter Perioperative Outcomes Group (MPOG) Perioperative Clinical Research Committee. Incidence, predictors, and outcome of difficult mask ventilation combined with difficult laryngoscopy: a report from the multicenter perioperative outcomes group. Anesthesiology. a report from the multic

PubMed Abstract | Publisher Full Text

5. Cattano D, Killoran PV, lannucci D, et al: Anticipation of the difficult airway: preoperative airway assessment, an educational and quality improvement tool. Br J Anaesth. 2013; 111(2): 276-85.

PubMed Abstract | Publisher Full Text | Free Full Text

6. Peterson GN, Domino KB, Caplan RA, et al: Management of the difficult airway: a closed claims analysis. Anesthesiology. 2005; 103(1): 33-9. PubMed Abstract | Publisher Full Text

7. Apfelbaum JL, Hagberg CA, Caplan RA, et al:: American Society of Anesthesiologists Task Force on Management of the Difficult Airway. Practice guidelines for management of the difficult airway: an updated report by the American Society of Anesthesiologists Task Force on Management of the Difficult Airway. Anesthesiology. 2013; 118(2): 251-70. Difficult Airway. Anesthesiology. 2013; 118
PubMed Abstract | Publisher Full Text

8. Kheterpal S, Martin L, Shanks AM, et al:: Prediction and outcomes of impossible mask ventilation: a review of 50,000 anesthetics. Anesthesiology. 2009; 110(4): 891-7. PubMed Abstract | Publisher Full Text

9. Roberts S, Cyna AM, Walsh JP, et al:: Assessment of anaesthetists' ability to predict difficulty of bag-mask ventilation. Br J Anaesth. 2013; 111(4): 676-7. PubMed Abstract | Publisher Full Text

10. Na JU, Han SK, Choi PC, et al:: Influence of face mask design on bagvalve-mask ventilation performance: a randomized simulation study. Acta Anaesthesiol Scand. 2013; 57(9): 1186-92. PubMed Abstract | Publisher Full Text

11. Joffe AM, Hetzel S, Liew EC: A two-handed jaw-thrust technique is superior to the one-handed "EC-clamp" technique for mask ventilation in the apneic unconscious person. Anesthesiology. 2010; 113(4): 873-9. PubMed Abstract | Publisher Full Text

12. Warters RD, Szabo TA, Spinale FG, et al.: The effect of neuromuscular blockade on mask ventilation. Anaesthesia. 2011; 66(3): 163-7. PubMed Abstract | Publisher Full Text

13. Gonzalez H, Minville V, Delanoue K, et al:: The importance of increased neck circumference to intubation difficulties in obese patients. Anesth Analg. 2008; 106(4): 1132-6.

PubMed Abstract | Publisher Full Text

14. Leoni A, Arlati S, Ghisi D, et al.: Difficult mask ventilation in obese patients: analysis of predictive factors. Minerva Anestesiol. 2014; 80(2): 149-57. PubMed Abstract

15. Corso RM, Petrini F, Buccioli M, et al:: Clinical utility of preoperative screening with STOP-Bang questionnaire in elective surgery. Minerva Anestesiol. 2014: 80(8): 877-84 PubMed Abstract

16. Youden WJ: Index for rating diagnostic tests. Cancer. 1950; 3(1): 32-35. PubMed Abstract | Publisher Full Text 


\section{Open Peer Review}

\section{Current Peer Review Status:}

\section{Version 1}

Reviewer Report 17 October 2014

https://doi.org/10.5256/f1000research.5471.r6308

(C) 2014 Matioc A. This is an open access peer review report distributed under the terms of the Creative Commons Attribution License, which permits unrestricted use, distribution, and reproduction in any medium, provided the original work is properly cited.

\section{Adrian Matioc}

University of Wisconsin School of Medicine and Public Health, William S. Middleton Memorial Veterans Medical Center, Madison, WI, USA

There is today an increasing interest in studying difficult face mask ventilation. Cattano et al. present a retrospective study derived from a database built of elective cases. There are several points I want to make:

First, the study used a "real world clinical setting" confirming that in the daily practice difficult face mask ventilation is not a rare occurrence.

Second, it introduced an objective assessment tool for the difficult face mask ventilation: capnography (further comment from the authors regarding this tool would be appreciated).

Third: six out of the seven independent risk factors for the difficult face mask ventilation (age, BMI, neck circumference, presence of facial hair, perceived short neck, OSA) that were identified and then applied to evaluate a predictive model can be easily assessed or inferred with a clinical exam on an unconscious patient thus having probably a role in the outside of the operating room setting too.

Fourth: the study confirms the importance of neck circumference, BMI and OSA in the difficult face mask ventilation paradigm. It is known that these clinical settings are plagued by inspiratory and expiratory obstruction at the soft palate level that does not respond to airway manoeuvres. The soft palate obstruction (relevant for nasal ventilation) can be by passed by committing to oral ventilation (by opening the mouth with an oropharyngeal airway). ${ }^{12}$ It may be appropriate to recommend in these clinical settings a first (optimized) face mask ventilation attempt with an oropharyngeal airway in situ.

\section{References}

1. Sato Y, Ikeda A, Ishikawa T, Isono S: How can we improve mask ventilation in patients with 
obstructive sleep apnea during anesthesia induction?. J Anesth.2013; 27 (1): 152-156 PubMed Abstract | Publisher Full Text

2. Buffington CW, Wells CMQ, Soose RJ: Expiratory Upper Airway Obstruction Caused by the Soft Palate during Bag-Mask Ventilation. Open Journal of Anesthesiology. 2012; 2 (2): 38-43 Publisher Full Text | Reference Source

Competing Interests: Royalties for the ergonomic face mask

\section{I confirm that I have read this submission and believe that I have an appropriate level of expertise to confirm that it is of an acceptable scientific standard.}

Author Response ( ) 17 Oct 2014

Davide Cattano, University of Texas Medical School at Houston, Houston, USA

We are grateful for Dr Matioc comments which endorse our findings while offring an opportunity for further discussion. We do agree with Dr Matioc about the importance of properly monitoring ventilation, which may not always be possible simply by utilizing a capnometry tool, and current investigations are actually looking at other type of devices, particularly in the postoperative arena, where airway obstruction may still occur. In the operating room the presence of capnometry combined with spirometry is a complete tool. Regarding airway adjuncts, I agree that an oral airway cannula should be promptly used, as in fact was one of the limitations of our investigation, since it is part of common airway management pathways, however I would consider also a nasal airway, if available and not concerning trauma, for a better and proper management of ventilation.

Competing Interests: No competing interests were disclosed.

Reviewer Report 28 August 2014

https://doi.org/10.5256/f1000research.5471.r5963

(C) 2014 Doyle D. This is an open access peer review report distributed under the terms of the Creative Commons Attribution License, which permits unrestricted use, distribution, and reproduction in any medium, provided the original work is properly cited.

\section{John Doyle}

Department of General Anesthesiology, Cleveland Clinic Main Campus, Cleveland, OH, USA

This is an important contribution to the difficult airway literature and will be helpful to clinicians wanting a means to predict that mask ventilation may be a problem following the induction of general anesthesia. While the limitations of the study are correctly stated (see p. 5) I would add some wording to this section to re-emphasize that this was a retrospective study and that the use of neuromuscular blocking drugs was not part of the analysis. In addition, since a great many cases of difficult mask ventilation vanish following the administration of neuromuscular blocking drugs, I recommend that the discussion on this particular issue should be discussed in a bit more 
detail, perhaps making reference to one or more of the following recent publications.

Xue FS, Cheng Y, Li RP: Facemask ventilation and neuromuscular blockade in anesthetized patients. Anesthesiology. 2013;118(4):991-2. doi: 10.1097/ALN.0b013e3182874628

Richardson MG, Litman RS: Ventilation before paralysis: crossing the Rubicon, slowly. Anesthesiology. 2012; 117(3):456-8. doi: 10.1097/ALN.0b013e318266868f

Engelhardt T, Weiss M: Difficult mask ventilation and muscle paralysis. Anesthesiology. 2013; 118 (4):994. doi: 10.1097/ALN.0b013e3182874659.

Priebe HJ: Ventilation before paralysis. Anesthesiology. 2013; 118(4):992-3. doi:

10.1097/ALN.0b013e3182874642.

Competing Interests: No competing interests were disclosed.

I confirm that I have read this submission and believe that I have an appropriate level of expertise to confirm that it is of an acceptable scientific standard.

Author Response ( ) 28 Aug 2014

Davide Cattano, University of Texas Medical School at Houston, Houston, USA

I am grateful to Dr Doyle for his review, comments and, in particular, for the detailed references.

Indeed the avoidance of muscle relaxation from the analysis was a major "missed" undertaking, since you are completely right about the important effects of muscle relaxation. We made sure that such information was immediately available to the reader as a methodological point, and we kept it short in the discussion to focus on positive findings. It is always of importance to report both positive and negative findings; however, the lack of such related data was missing information rather than negative. We appreciate, however, your comment giving an opportunity for the reader to understand the importance of such a factor. We also need to remind the reader of the interesting aspect that muscle relaxation plays in difficult airway management and how it also plays a role in the DAW algorithms. It is not trivial to consider that our practice includes the establishment of an airway after a mask ventilation is achieved without the utilization of muscle relaxant at first (which we included as standard of care in our investigation) while muscle relaxant is utilized as a rescue for such events.

It is important to consider the evidence value of certain practices though - whether or not they not only make sense, but are of value for a safe and practical airway management. In fact, the controversy - as you elegantly point at with the references provided - is about giving muscle relaxant up front (which was part of anesthesia practice a few years ago). Based on experience, the question is rather: can I use muscle relaxant or not, and should I do an awake intubation (or other airway)? Also the major change that occurred from the recognition of airway related morbidity and mortality in the 80's and 90's and now, is the availability of extraglottic devices and new airway tools that have in fact improved our practice. 
Competing Interests: No competing interests were disclosed.

The benefits of publishing with F1000Research:

- Your article is published within days, with no editorial bias

- You can publish traditional articles, null/negative results, case reports, data notes and more

- The peer review process is transparent and collaborative

- Your article is indexed in PubMed after passing peer review

- Dedicated customer support at every stage

For pre-submission enquiries, contact research@f1000.com 